\title{
Emotional Intelligence and Extended Service Profit Chain in Telecom Industry in Oman - An Empirical Validation
}

\author{
Mohammad Sultan Ahmad Ansari ${ }^{1}$, Jamal A. Farooqui ${ }^{2}$, Said Mohammed Gattoufi ${ }^{3}$ \\ ${ }^{1}$ Manager - Wholesale Business Unit, Oman Telecommunications Company, Sultanate of Oman \\ ${ }^{2}$ Professor, Department of Business Administration, Aligarh Muslim University, Aligarh, India \\ ${ }^{3}$ Professor at Institut Superieur de gestion de Tunis, Institut Superieur de gestion de Tunis, Sabanci University, \\ Le Bardo, Tunis Governorate, Tunisia
}

Correspondence: Mohammad Sultan Ahmad Ansari, Manager - Wholesale Business Unit, Oman Telecommunications Company, Sultanate of Oman.

Received: November 20, 2017

Accepted: January 15, 2018 Online Published: February 19, 2018

doi:10.5539/ibr.v11n3p133

URL: https://doi.org/10.5539/ibr.v11n3p133

\begin{abstract}
A research study was initiated to investigate the influence and impact of Emotional Intelligence (EI) on extended Service Profit Chain (SPC) model in a telecom service industry in Oman. The operations management literature frequently exhorts that in addition to quality compliance, customer satisfaction, retention some attention to be devoted to attributes like employees satisfaction and loyalty as well. Accordingly, the SPC integrates EI as a pivotal component and has been in wide use for studying mutual linkages between employees and customers. The present study empirically examines the suitability and usefulness of this model in telecommunications industry, by collecting feedback about various attributes associated with from entities in both upstream and downstream paths viz. Original Equipment Manufacturers (OEM), Service Providers (SP) and Customers. Using a battery of carefully-crafted, inter-linked hypotheses by thorough statistical analysis of the survey data was made to validate the assumptions and the soundness of three-tier architecture of SPC. The proposed research framework demonstrated that Service Quality (SQ) of upstream OEMs increases in proportion to the SQ and employee loyalty of SPs, which in turn generates satisfaction and loyalty among downstream customers. Interestingly, loyalty among downstream customers diffuses or propagates upward, translating into higher sales and performance for upstream OEMs. These findings suggest that EI is a benevolent, binding force and plays an invisible hand, in enhancing internal performance of an organization. By embracing extended SPC model, service industries are bound to gain competitive advantage and unleash firm profitability.
\end{abstract}

Keywords: emotional intelligence, service quality, employee satisfaction, employee loyalty, customer satisfaction, customer loyalty, profitability

\section{Introduction}

Expression of emotions in human beings and animals has been experienced over a long period of time in the course of evolution. The concept of EI goes way back to the days of Charles Robert Darwin (1872), who first identified that "human" qualities such as courage and devotion, including pride, jealousy and shame, existed and persisted in animals too. Subsequently, he hypothesized that human emotional expressions have evolved over time because of its links with reactions having adaptive or survival value. In everyday life, one occasionally comes across a brilliant student performing badly in school or an intelligent workers ending up with small gain in their career. What is required to achieve success in life, it is said, is a combination of competencies, including control of emotions and an exceptional understanding of social behaviors.

Daniel Goleman's (2004) widely accepted model, which was first published in Harvard Business Review (HBR) on EI and leadership, "What Makes a Leader?", highlighted five essential components of EI at work, viz. Self-Awareness, Self-Regulation, Motivation, Empathy and Social skills. He maintains that proper development of these skills would add value to an individual and it can lead to corporate success in terms of improved performance. In professional life, knowledge of company's and competitors' products and services would improve one's social intelligence. According to (Goleman and Boyatzis. 2008), there is a large performance gap between socially intelligent and not-so-intelligent leaders. Hence, it is expected that such socially-aware and 
emotionally intelligent leaders will be in a better and stronger position to lead the team and would improve team performance in terms of productivity, profitability and emotional attachment with employees and customers. However, in some case exceptionally high intelligent person may not perform to the expectation and likely to be on risk. According to Karpinskia et al (2017) high intelligence are at significantly greater risk for the examined psychological disorders and physiological diseases.

The pressures of globalization, passionate competition, and growing instability in market force many organizations to add value to their products and services in order to retain customers' loyalty (CL), overcome customers churn, and to ensure enhanced market share, revenue and profitability. A theory proposed by (Heskett el. al., 1994), named SPC, is widely accepted as a barometer for measuring overall performance of a business organization. This theory lays out a set of comprehensive links among many attributes like internal SQ that improves employees' satisfaction (ES), employees' loyalty (EL), and external SQ, customers' satisfaction (CS), CL, sales from repurchase \& referrals (SR) and firm's profitability (FP). Although relationships depicted in SPC have not been widely validated in all types of industries, researchers are persistently and vigorously working to provide evidence of such relationships. A few research works are available that tested SPC's chain in service industries but only limited studies has been conducted, particularly in telecom service industries. To the best of our knowledge none of them has corroborated the impact of EI on SPC's and extended SPC's attributes. However, a research by (Ansari, et al 2016), EI and employees performance are interlinked and found that employees are valuable assets in a service industry, and growth of industry depend on employees' commitment.

\subsection{Research Questions}

This research work sets out to empirically validate the impact of EI on extended SPC's attributes. It evaluates the influence of EI on SQ, ES, EL, CS, CL, SR, and FP. Hence based on the objectives of the study, the following Research Questions (RQs) were raised:

RQ1: Does EI inspire ES and EL?

RQ2: Does internal $S Q$ inspire ES and EL?

RQ3: Do ES and EL have any bearing on CS and CL?

RQ4: Do CS and CL induce positive word of mouth that improves sales?

RQ5: Does positive word of mouth increase sale revenue and enhance profitability?

\subsection{Rationale for the Study}

Earlier researches were limited in scope and most of the studies were focused only on ES, CS, SQ, or employee evaluation of customers' perceptions of SQ. In majority of the cases, data were obtained either from a single source, (e.g., Service Providers' (SP's) employees evaluating customers' perceptions of SQ and their own satisfaction and loyalty), or in some other cases from customers evaluating SQ of their SPs and their own loyalty. In an attempt to enlarge the scope and remove the limitations of earlier works, the present researchers have decided to conduct a study to test the influence of EI on extended SPC's chain. Hence, this study was designed to evaluate the complete chains of services, i.e., services provided by OEMs to SPs and services provided from SPs to End Users (EUs), which authors addressed as an extended SPC's model. In this way, the present study has set out to accomplish a comprehensive validation of SPC in the telecommunications service industry.

\subsection{Objectives of the Study}

This research is an attempt to assess the impact and probe the influence of EI on extended SPC's attributes and to understand whether and how far these attributes hold well in telecommunications services chain. This chain includes infrastructure like hardware, software and firmware supplied by OEMs to SPs and by SPs to EUs and services like voice $\&$ data for post $\&$ prepaid users, private \& corporate leased lines, Value Added Services television, pre \& postpaid roaming services and so on. To embark on such a study, the following desiderata set the stage for the investigation to follow, and guide the articulation of assumptions and formulation of hypotheses, which are later statistically tested and validated:
a. Stimulus of EI on SQ.
b. Influence of SQ on ES and EL.
c. Impact of ES and EL on CS and CL.
d. Bearing of CS and CL on SR, and
e. Effect of SR on increase in revenue and FP. 
The following sections present the theoretical background, the framework proposed, the hypotheses developed and the methodologies adopted in this research. It further continues to discuss the results obtained and the scope for future work.

\section{Theoretical Background, Proposed Model and Hypotheses Development}

\subsection{Service Profit Chain}

Schlesinger and Heskett (1991) argued that there is a "cycle of failure," i.e., although service companies invest in employees in terms of training or skills development, and if employees are paid less than the market rate, they will get dissatisfied and/or become even frustrated. Consequently, their loyalty to the company will wear thin in time, leading to increased employee turnover and poor performance of the company; this will in turn kick off another cycle of employee recruitment and training. So it is imperative that ES be accorded due importance and it can be maintained and sustained only by integrating employees' efforts into the service delivery system. This will undoubtedly have positive impact on SQ, CS, and CL, and eventually will have beneficial implications on financial performance.

Subsequently, (Heskett et al, 1994) extended SPC framework through an article published in HBR, "Putting the Service-Profit Chain to Work", wherein they hypothesized that a firm's profitability and growth will increase if operations and human resources management are integrated well. Their work provided an integrated and holistic framework for understanding how operational performance relates to customers' perceptions and behavior and how these later translate into profits. It is assumed that all the links in the chain are equally important, and that it is necessary to devote close attention to each link in order to understand the overall functioning of SPC.

Some researchers have tested the SPC's links and their findings conform to its predictions. According to (Walker et al., 2006), SPC is based on the premise that a firm's profitability derives from CS and CL. Researchers such as (Kamakura et al., 2002) and (Loveman, 1998) called for simultaneous testing of several links based on multiple data sources within SPC. On the other hand, (Yee et al., 2011) added that ES was crucial in achieving SQ and profitability in a service industry. Similarly, the published work in HBR by (Fred Reichheld, 2006) "The Ultimate Question", it is observed that firms with loyal customers tend to spend much less on marketing and acquisition of new customers than do their competitors. Instead, these firms focus intensely on serving existing customers and are highly selective in pursuing new customers, in order to promote the emergence of "loyalty leaders". His study led him to identify relationship between CS and customers churn or defection to their competitors.

Further (Homburg et. al. 2009) simultaneously tested SPC's paths on multiple links by combining data from employees, customers and companies, and found that positive role of social identification construct led to positive market and financial outcomes. Researchers who obtained similar anecdotal evidences include (Kassinis and Soteriou, 2003); (Xu, 2005); (Walker et al., 2006); (Maritz and Nieman, 2008); (Yee et al., 2008, 2009, 2011); (Theoharakis et al., 2009); (Lee, 2013); and (Chu et al., 2013). The SPC's attributes were validated by (Bressolles and Durrieu, 2015) in an online retailing context, which demonstrated strong relationship between e-service quality dimensions and e-satisfaction towards customers.

Researchers who hold contrarian views about SPC's attributes, stating that the theory remains in a formative stage and is un-authenticated or requires further research, include (Silvestro and Cross, 2000), (Kamakura et al., 2002), (Sharif, 2009), (Evanschitzky et al., 2012). The research by (Chicu et al., 2016)0 suggested that the SPC approach holds good in call centers with a number of added nuances, and proposed that further research is required to determine how the model can be best adapted to explain the peculiarities of the evolving service economy.

\subsection{Theoretical Background}

Only a limited research exists on testing of SPC's attributes in telecommunications service industries. Researchers conducted by (Sharif, 2009) that empirically validated the links from SPs to EU found that satisfaction-driven loyalty could be due to restricted changeover possibilities. In the backdrop of this situation, it is found that only a few studies have been conducted in telecommunications services industries for testing of SPC attributes, and to the best of the present authors' knowledge, no work has been reported yet that evaluates the impact of EI on extended SPC's model. In the present research scenario, there clearly exists a need to conduct a study of the extended SPC's model and the present work is expected to fill this void. The following sections present the details of such a study conducted in a telecom company in the Sultanate of Oman.

\subsection{Variables of the Study}

The primary sources of data originate from OEMs, SPs, and EUs, the three main players in this study. As a 
preliminary step to gathering data for statistical analysis, various relevant attributes associated with them were first identified and were then tagged with suitable subscripts to identify the source of data. The following three short paragraphs describe the mapping and notational scheme adopted

Variables with subscripts standing for OEMs include: OEMs' employee satisfaction $\left(\mathrm{ES}_{\mathrm{M}}\right)$, OEMs' employee loyalty $\left(\mathrm{EL}_{\mathrm{M}}\right)$, OEMs' service quality $\left(\mathrm{SQ}_{\mathrm{M}}\right)$, OEM's customer satisfaction $\left(\mathrm{CS}_{\mathrm{M}}\right)$, OEMs' customer loyalty $\left(\mathrm{CL}_{\mathrm{M}}\right)$, OEMs' sales from repurchases \& referrals $\left(\mathrm{SR}_{\mathrm{M}}\right)$ and $\mathrm{OEMs}$ ' firm's profitability $\left(\mathrm{FP}_{\mathrm{M}}\right)$, where $\mathrm{SQ}_{\mathrm{M}}$ and $\mathrm{SR}_{\mathrm{M}}$ represent OEM's perception of SQ delivered to SPs and expected sales from repurchases and referrals due to SPs.

a. Variables with subscripts standing for SPs include: SPs' employee satisfaction $\left(\mathrm{ES}_{\mathrm{S}}\right)$, SPs' employee loyalty $\left(\mathrm{EL}_{\mathrm{S}}\right)$, SPs' service quality $\left(\mathrm{SQ}_{\mathrm{s}}\right)$, SPs' customer satisfaction $\left(\mathrm{CS}_{\mathrm{S}}\right)$, SPs' customer loyalty $\left(\mathrm{CL}_{\mathrm{S}}\right)$, SPs 'sales from repurchases and referrals $\left(\mathrm{SR}_{\mathrm{S}}\right)$, and $\mathrm{SPs}$ ' firm's profitability $\left(\mathrm{FP}_{\mathrm{S}}\right)$. The $\mathrm{SQ}_{\mathrm{S}}$ represents two sets of data, i.e., SP's view of SQ offered by OEMs and SPs' perceptions of the SQ delivered to $\mathrm{CS}_{\mathrm{EU}}$. In the same way, $\mathrm{SR}_{\mathrm{S}}$ represents two sets of data, i.e., SPs' repurchase intention of OEMs' services and End Users satisfaction $\left(\mathrm{CS}_{\mathrm{EU}}\right)$ and repurchase intentions from SPs' point of view.

b. Similarly, variables with subscripts allotted for $\mathrm{EU}_{\mathrm{S}}$ include: EUs' service quality $\left(\mathrm{SQ}_{\mathrm{EU}}\right)$, End Users satisfaction $\left(\mathrm{CS}_{\mathrm{EU}}\right)$, customers and end users' loyalty $\left(\mathrm{CL}_{\mathrm{EU}}\right)$ and $\mathrm{EUs}$ repurchase intentions through positive word-of-mouth $\left(\mathrm{SR}_{\mathrm{EU}}\right)$ for SPs.

(A list of all the variables used in this study is collected in a table, appearing towards the end of this paper.)

Having provided a brief theoretical background and defined the variables involved in this study, the paper proceeds to discuss the proposed model, working hypotheses, methodologies, and testing of hypotheses using various tools in Statistical Package for the Social Science (SPSS) software. Subsequently, results are discussed, followed by its limitations and scope for future research.

\subsection{Proposed Model}

Figure-1 represents the proposed model featuring prominently EI and its associated components that are inspired by the attributes of extended SPC model. The model may be viewed as consisting upstream and downstream paths.

\section{Influence of El on extended SPC's attributes}

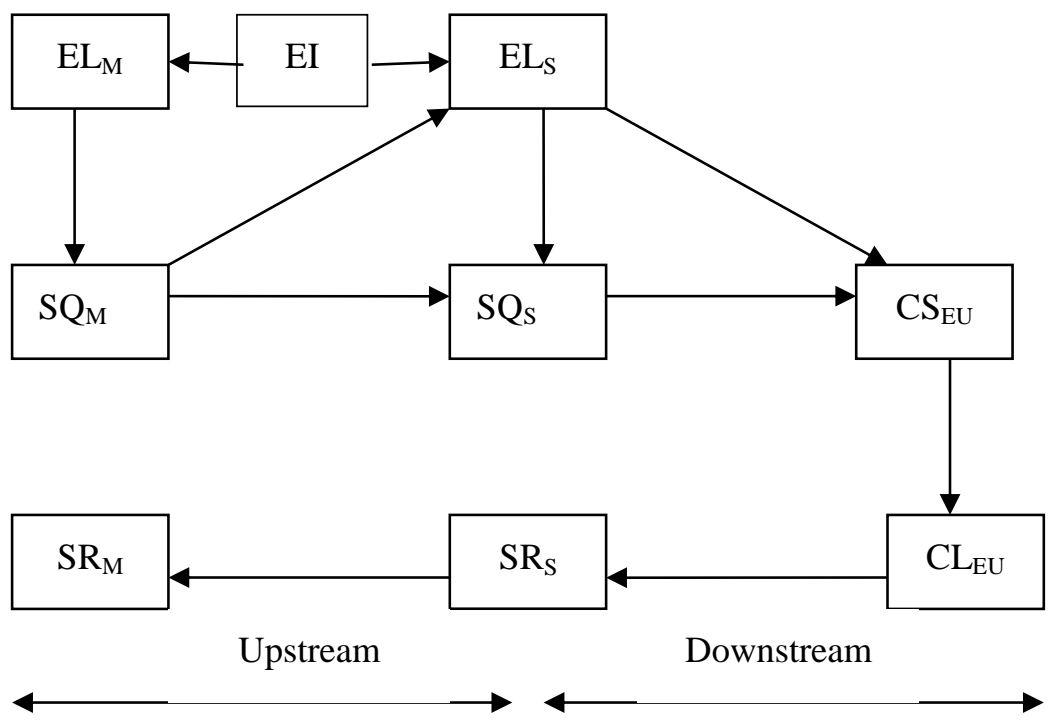

Figure 1. Proposed Model

The upstream path starts with EI, and extending over OEMs' attributes $\mathrm{EL}_{\mathrm{M}}, \mathrm{SQ}_{\mathrm{M}}$, and $\mathrm{SR}_{\mathrm{M}}$, joins with $\mathrm{EL}_{\mathrm{S}}, \mathrm{SQ}_{\mathrm{S}}$, and $\mathrm{SR}_{\mathrm{S}}$, the attributes of SPs; the downstream path is comprised of $\mathrm{CS}_{\mathrm{EU}}, \mathrm{CL}_{\mathrm{EU}}$ related to the traits of $\mathrm{EU}$, also joining with $\mathrm{EL}_{\mathrm{S}}, \mathrm{SQ}_{\mathrm{S}}$, and $\mathrm{SR}_{\mathrm{S}}$, the very same attributes of SPs. Thus, as can be seen, the attributes of SPs act as interface elements or functions as conduits for and between these two paths. In other words, these two paths effectively meet and merge with the attributes of SPs. It is this model which is examined in depth, and which will 
be verified and validated by testing a group of hypotheses that connect multiple combinations of SPC's variables. The following sections provide the details of this study.

\subsection{Hypotheses Development}

The present work becomes significant and important in that the deficits in the efforts of most of the previous researchers are filled in, and a thorough attempt has been made to address the limitations of their work for the first time in an inclusive manner. The earlier researches were focused mainly on discrete and distinct aspects of SPCs with data coming from independent disconnected entities. In the present study, data are taken from all the three central overarching players in the model viz OEMs, SPs and EUs, viewed in a holistic way. For example, in the earlier work, data were sourced only from SPs or in some cases from SPs and EUs combined. Also, in some cases studies were limited to only a few attributes of SPCs, though a few exceptions do exist in the literature. In contrast, in the present work, the statistical analysis of the data from all the three key players (OEMs, SPs and EUs) is carried out in a coherent, consistent and integrated manner in the form of upstream and downstream paths with multiple combinations of SPC's and extended SPC's attributes.

The study encompasses three major entities viz. OEMs, SPs and EUs. They form a continuous and comprehensive chain of services flowing from OEMs through SPs to EUs as a unified whole, with the structure of extended SPC model as elaborated in Figure-1 in place, the following nine hypotheses $\left(\mathrm{H}_{01}\right.$ to $\left.\mathrm{H}_{09}\right)$ are developed and explicated. They are then subject to standard statistical hypothesis testing using SPSS software with the aim of verifying and validating this model and its assumptions.

Hypothesis $\boldsymbol{H}_{01}$ : Influence of $\boldsymbol{E I}$ on $\boldsymbol{E} \boldsymbol{L}_{M}$ that affects $\boldsymbol{S} \boldsymbol{Q}_{M}$ : This hypothesis discusses the effects EI brings to bear upon upstream $\mathrm{EL}_{\mathrm{M}}$, which in turn influences $\mathrm{SQ}_{\mathrm{M}}$, which is due to the fact that elements of $\mathrm{EL}_{\mathrm{M}}$ are intertwined with $\mathrm{SQ}_{\mathrm{M}}$. The SQ remains paramount in the changing and challenging business environment. Professional companies usually develop a competency model to develop employees' skills with the aim of developing emotional and passionate attachments with employees in order to improve efficiency. Hence, for writing success stories managers shall integrate human skills, employees' competencies, and emotional intelligence. It would further build an exceptional understanding among the team and develop cohesive social fabric.

A few researchers have attempted to link job satisfaction, EL, CS, and CL with operational performance of company. Researcher (Yee et al., 2008) found strong evidence that supported the fundamental relationship among ES, SQ, CS, and FP. SQ can be improved by developing a friendly environment with employees and sharing their experiences. Hence, SQ can only be achieved through satisfied and loyal employees. Accordingly, it is posited that $E I$ influences $E L_{M}$ which in turn affects $S Q_{M}$.

Hypothesis $\mathrm{H}_{02}$ : Upstream $S Q$ and downstream $S Q$ : This hypothesis evaluates the effects of $\mathrm{SQ}_{\mathrm{M}}$ on $\mathrm{SQ}_{S}$ i.e. how OEMs' SQ influences SQs. In service industry, SQ begins with service encounter, i.e., when customers interact at an outlet with customer's champion. In telecom, SQ not only includes human interactions but network availability, capacity and reliability too contribute significantly in fulfilling SQ parameters. According to (Clements 2004), network performance includes quality of services that support the network.

It is not only demanded by customers but enforced by regulators, who are well versed with it. SQ parameters are generally updated on a periodical basis as key performance indicators. It evolves to become international and regional benchmark. In the event of non-compliance, regulators enforce penalties according to license conditions. The objectives of establishing such parameters are to ensure level playing field for all SPs, which facilitates EUs to receive optimal SQ at best price. Hence, SPs with OEMs' support need to develop their strategies in order to accomplish regulated KPIs. Conversely, (Onyeajuwa., 2017), research revealed that due to weak institutional structures, the regulator and mobile service providers do not hold ordinary consumer's interest.

In view of the established best practice and benchmark, employee involvement becomes all the more crucial.It can be accomplished by continuous skills development, improving internal SQ, which would enhance employees' motivation and their involvement. Hence, $\mathrm{SQ}_{M}$ will have positive influence on CSs. Therefore, $\mathrm{SQ}_{\mathrm{M}}$ is likely to influence $\mathrm{SQ}_{s}$. Accordingly, it is hypothesized that $\mathbf{S Q}_{\mathbf{M}}$ affects $\mathbf{S Q}_{\mathrm{s}}$.

Hypothesis $\mathrm{H}_{03}$ : Upstream SQ, EI and downstream EL: This hypothesis assesses the influence of $\mathrm{SQ}_{\mathrm{M}}$ on $\mathrm{EL}_{\mathrm{s}}$. Though it appears platitudinous to say that people like to work harder and perform better when they like and enjoy their work. They would prefer to work for the same employer even when enticed by competitors with higher pay and perks. This state of affairs can be obtained only when the employer establishes strong relationships and develops strong emotional bonds with employees. Leaders need to be seen caring and should assiduously make efforts to garner employees support by developing strong relationship. According to (Goleman, 
2004), EI has direct, strong ties with business results and it is worth pursuing for both individuals and organizations.

The employees' engagement is essential at all levels in a service organization. Particularly in telecom industry, services provided by OEMs and SPs need cohesive human interaction with employees and customers. Cohesive relationship with employees will pave the way for achieving higher network quality, which might not be possible in its absence. Excellent relationship would improve network performance and reliability so that CSs improves. Improved CSs is likely to develop positive image of SPs. Improved $\mathrm{SQ}_{\mathbf{M}}$ will motivate $\mathrm{SP}_{\mathrm{S}}$ employees in fulfilling customers' demands.

Quality remains a buzzword in a service industry and so is the network quality in telecom service industry. According to (Amini and Saraei, 2012) among the components of quality indices from the most to the least important items were: reliability, tangibility, accountability, guarantee, and empathy consecutively. The service industry shall strive to offer best value for money in order to fulfill EUs expectations. It would lead to purchase, repurchase and positive word of mouth, leading to improved $\mathrm{SR}_{\mathrm{EU}}$.

SPs as being OEMs' customer, the SPs' employees assess network quality and their service encounter with OEMs. Their evaluation of different aspects of network quality will principally influence $\mathrm{SQ}_{\mathrm{M}}$. The SPC theory holds that CS leads to CL, and in this scenario the downstream employees are the SPs' employees. Hence, once SPs' employees are satisfied with network quality, they will be loyal $\left(E L_{S}\right)$ to their company. Accordingly, it is posited that $\mathbf{S Q}_{\mathbf{M}}$ would influence $\mathbf{E L}_{\mathbf{S}}$.

Hypothesis $H_{04}$ : Downstream EL and downstream SQ: EL and SQ are valuable business assets in a service industry. EL can be achieved by implementing appropriate human resource policies for achieving improved internal SQ. It would require highly coordinated and timely interactions between customers and service employees.

Interactions with employees vary from sector to sector. Industries like telecom, education, health \& beauty care require extremely coordinated efforts between service employees and customers. This can be obtained through cohesive human interaction. In certain sectors manual processes are predominant, whereas in the telecom, manual as well as technological supports are equally involved. It requires high quality coordinated human interaction as well as high quality network, in order to accomplish the vital task of enhancing SQ. Since service industries are time sensitive, its delivery should be in near real time. A technology-driven service delivery system cannot match customers' expectations and improve their perceptions unless service employees are highly skilled, satisfied \& loyal and are willing to put their best in achieving SQ.

It would remain a challenge for service organizations for achieving competitive advantage unless employees and customers together are managed at the same time and kept satisfied too. Service employees closely associated with customers may become foremost contributors in meeting customers' expectations. Accordingly, it is proposed that $\mathbf{E L}_{\mathrm{S}}$ enhances $\mathbf{S Q}_{\mathrm{S}}$.

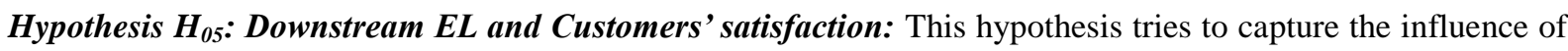
ELs on $\mathrm{CS}_{\mathrm{EU}}$. According to (Theoharakis et al., 2009), satisfied and loyal employees fare better in developing relationships with customers and strategic partners, and those authors further endorse that increase in CS and CL ultimately leads to better financial performance. Service companies should develop a cohesive environment for winning EL for eventually delivering an exceptional experience to the customers. Satisfied employees will have high morale, will perform well, share their experience with colleagues, and contribute positively for the firm's success..

The other important factors for developing strong emotional bonds with the employees are company's environment, employee's empowerment and corporate culture. The long-lasting emotional bonds shall improve ES, and EL. An improved employee's relationship can be achieved by meeting employees' justified demand. Hence, in the long run, EI plays a significant role in developing ES and CS that would eventually improve profitability. Accordingly, it is posited that $\mathbf{E L}_{\mathbf{S}}$ enhances $\mathbf{C S}_{\mathbf{E U}}$.

Hypothesis $H_{06}$ : Downstream $S Q$ and customers' satisfaction: The proposition considered here is that $\mathrm{SQ}_{S}$ enhances $\mathrm{CS}_{\mathrm{EU}}$. The $\mathrm{SQ}$ is a multi-dimensional concept, mainly comprising perceived and received quality, purchase and repurchases intentions, positive word of mouth, customer behavior and value for the money. In the absence of these dimensions, customers may not be satisfied even if the delivered SQ is of higher standard. According to (Lee, 2013), SQ is a significant antecedent of CS and CL. Perceived SQ is becoming an important aspect in service industry..

The presence of an effective service climate comprising employees' attitude, customers' experiences, and the 
understanding of local culture and tradition shall be advantageous to service providers. According to (Pilkington and Chai, 2008), any service is likely to be influenced by the local culture and environment. Hence, service employees shall adapt to the local culture, which can be developed with right attitude and adopting friendly solving approach. An appropriate attitude can play a vital role in a service delivery system. It can delight customers and can work as a cohesive force between customers and SPs. The right service attitude will improve $\mathrm{CS}_{\mathrm{EU}}$, generate customers' repurchase intentions and ultimately maximize shareholders' value. Accordingly, it is predicted that downstream $\mathbf{S Q}_{\mathrm{S}}$ improves $\mathbf{C S}_{\mathrm{EU}}$.

Hypothesis $\mathrm{H}_{07}$ : Customers satisfaction and Customers loyalty: The prerequisite for success in a service industry is to attain highest level of CS and CL and it can be achieved only through highly professional approach. The best way of achieving sustainable growth is through unceasing innovation and willingness to learn from customers' experiences. Therefore, services packaging shall be based on projected growth and futuristic demand.

The achievement of projected growth would require groundbreaking ideas from internal or external customers and can be gathered through official or semiofficial channels. Customer Relationship Management (CRM) and internal feedback can be used to collect data from external and internal customers respectively. According to (Rygielski et al., 2002), customers and business should interact more frequently in order to capture and analyze massive amounts of customer information. CRMs' features of on-line shopping, e-learning, e-purchasing, and e-commerce could play a vital role in gathering data on futuristic demand.

SPs need to develop excellent relationship with customers and must perform exceptionally well for achieving $\mathrm{CS}_{\mathrm{EU}}$. It can be realized through capturing and captivating customers by means of adaptive selling and by promoting the feeling of group-belongingness. As a part of adaptive selling, a company may implement a multiple-channel strategy to reach out to customers instead of customers approaching a company. However, in the long run, $\mathrm{SQ}$ matters much and by enhancing $\mathrm{CS}_{\mathrm{EU}}$, one finds $\mathrm{CL}_{\mathrm{EU}}$ also growing. Accordingly, $\mathbf{C S}_{\mathrm{EU}}$ is expected to influence $\mathbf{C L}_{\mathrm{EU}}$.

Hypothesis $\mathrm{H}_{08}$ : Customers Loyalty leads to downstream sales from repurchases and referrals: It is presumed that once customers are satisfied they will be loyal. It will lead to more purchases, repurchases and positive word-of-mouth to other potential customers. Hence, CL shall be given top priority for retaining market share and future growth. According to (Duffy, 1998), building CL is a business strategy and not merely a marketing program. Particularly in a competitive market, maintaining CL remains a challenge and it can be met by effectively implementing right business strategies, such as continuous customers' feedback on the current and futuristic products and/or services. The evaluation and implementation of customer's suggestion mechanisms would build brand image and create brand ambassadors. According to (Cliffe and Motion, 2005), brands can build points of distinction and unique experiences. Brand image minimizes churn, reduces cost in attracting new customers and ultimately stimulates purchase \& repurchase. Regular and frequent purchases contribute to revenue and profitability of the firm.. Hence, it is predicted that $\mathrm{CS}_{\mathrm{EU}}$ loyalty leads to downstream sales from repurchases and referrals.

Hypothesis $H_{09}$ : Downstream sales from repurchases and referrals affect upstream sales from repurchases and referrals: The expected relationship is that $\mathrm{SR}_{\mathrm{S}}$ will have a direct impact on $\mathrm{SR}_{\mathrm{M}}$. OEMs and $\mathrm{SPs}$ need to increase market share by meeting and exceeding customers' expectations, which can be achieved through creating continuous customers' demand for services like voice, data \& leased line, on demand movies, VAS, or roaming services.

An increasing $\mathrm{SR}_{\mathrm{S}}$ would demand higher bandwidth and can be provided, thanks to the technological advancement in high data transmission. Speed is growing day-by-day in wired and wireless technologies. Hence, $\mathrm{SR}_{\mathrm{M}}$ would increase due to enhanced network features and due to support of next-generation networks (NGN). Therefore the OEMs need to invest substantially in research and development $(\mathrm{R} \& \mathrm{D})$ in order to implement advanced features. These features are designed to meet and exceed the never-ending customers' demands. They are getting ever hungry for higher resolution and higher date speeds, wherever they are: while at home, office or on the move.

Hence, OEMs should be in a position to improve SQ in terms of higher bandwidth for content delivery that would increase SPs sales. According to (Sugai and Kim, 2008) stronger loyalty existed with content delivered via the mobile phone and content provider service quality. This in turn enhances $\mathrm{CS}_{\mathrm{EU}}, \mathrm{CL}_{\mathrm{U}}$ and $\mathrm{SR}_{\mathrm{EU}}$, thereby ultimately increasing $\mathrm{SR}_{\mathrm{M}}$. According to (Williams. and Naumann, 2011), customers' satisfaction increases repurchase and firms revenue. Hence, once $\mathrm{CS}_{\mathrm{EU}}$ are satisfied, it will lead to higher $\mathrm{SR}_{\mathrm{S}}$ that will in turn enhance $\mathrm{SR}_{\mathrm{M}}$. Accordingly, it is predicted that downstream sales from repurchases and referrals affect upstream sales from repurchases and referrals. 


\section{Research Methodologies}

The study seeks to understand the impact of EI on extended SPC. The primary data came from the field survey conducted in the years 2012 and 2013 by collecting feedback from 888 respondents covering both upstream and downstream paths of extended SPC chain.

\subsection{Sampling}

All possible efforts were made to collect balanced samples representing all segments of the population. A prior consent was taken from OEMs and SPs for their participation. It was estimated that the total number of OEMs' and SPs' employees were approximately 600 and 4,400, respectively. And the estimated numbers of EUs using one or more telecom services were approximately 2 million out of the total estimated population of 3.5 millions.

It was proposed to collect a minimum of 60 (Yee et al., 2011), 176 (Khatibi, 2002) and 600 (Homburg et al., 2009) samples from OEMs, SPs, and EUs respectively. And Yee et al., (2011) found that sample sizes of 45 from agency services were considered adequate for their research. In this study, OEM's functions were considered to be similar to agency services. Hence, it is proposed to consider a minimum of 60 valid samples from OEMs. In a similar way, sample sizes for SPs and EUs were chosen based on earlier research.

Table 1. Target segments, population, sample size, administered and retrieved questionnaires

\begin{tabular}{cccccc}
\hline $\begin{array}{c}\text { Target } \\
\text { Segments }\end{array}$ & Population Size & $\begin{array}{c}\text { Proposed Sample } \\
\text { Size }\end{array}$ & Administered Questionnaires & $\begin{array}{c}\text { Retrieved } \\
\text { Questionnaires }\end{array}$ & Response Rate \\
\hline OEMs & 600 & 60 & 100 & 66 & $66 \%$ \\
SPs & 4,400 & 176 & 350 & 201 & $57 \%$ \\
CSs & $2,000,000$ & 600 & 1,000 & 621 & $62 \%$ \\
Overall & $2,005,000$ & 836 & 1,450 & 888 & $61 \%$ \\
\hline
\end{tabular}

The distribution of questionnaires for OEMs and SPs were proportionately administered in accordance with number of employees, functionality and hierarchical positions. Table-1 summarises target segments, population and sample sizes for each segment with number of questionnaire administered, retrieved, and response rate.

\subsection{Pilot Studies}

The rationale of a pilot study is to clarify or ensure whether respondents have correctly understood the context of questionnaires and to modify or adjust the instruments accordingly. Pilot studies were conducted for all the three sets of questionnaires, by randomly selecting 5 employees each from OEMs and SPs and 10 EUs. It took an average of 12-15 minutes to get responses on questionnaires, inclusive of the time spent for answering some queries raised by respondents. Clarifications and explanations were given during pilot studies and the same were incorporated in the final instrument to ensure improved consistency and comprehension on the part of respondents. This way the pilot studies provided valuable preliminary data or a 'sneak preview' that helped to fine tune research ideas and refine the approach followed in this research. It is also an opportunity to 'test the waters' before launching into the full-scale analysis and investigation.

\subsection{Data Collection Method}

Printed hard copies of questionnaires were circulated to OEMs and customers, whereas for SPs printed and limited intranet-based questionnaires were used. The number of hard copies and intranet based questionnaires were recorded as "Administered questionnaires". Questionnaires meant for OEMs, SPs, customers were named set 1 , set 2 , and set 3 respectively. Set 1 and 2 questionnaires were circulated to top and mid-level management, supervisors, and employees. The authors decided to approach OEMs and SPs directly for getting their feedback but for customers' feedback, external assistance was sought.

Set- 1 consisted of 33 questions, i.e. 5 questions each on ES, EL, SQ, CL, CS, and 4 questions each on SR and FP. Set 2 consisted of 43 questions, i.e. 10 more questions in addition to those in set-1, i.e. 5 questions each on SQ and CL. The purpose of adding these questions was to determine SPs' views on OEM's SQ and their likely loyalty with OEMs, and also to ensure that forward and reverse chains were evaluated from OEMs to EUs and vice versa. Finally, set 3 questionnaire included 19 questions, i.e. five each SQ, CS, and CL and four on SR.

Set-3 questionnaires were circulated among selected segments of the entire country. Arabic remains the national language of the country and other widely spoken languages are English, Sohaili, and Balushi with some local dialects in the interior regions. Reaching a broad cross-section of the country, with numerous spoken languages and widely spread population across the country was a herculean task for the researchers. Therefore, assistance from friends and family was sought for EUs with the aim of achieving uniform feedback from the entire population. 


\section{Data Analysis and Results}

The questionnaires responses were recorded on a 5-point Likert scale, where 1 indicates total disagreement and 5 as total agreement. Descriptive statistics properties were obtained, such as arithmetic mean (AM) to determine how responses are centered, standard deviations (SD) to measure spread of the responses, and Cronbach's alpha $(\alpha>0.6)$ to examine the criterion of reliability. According to (Malhotra and Birk, 2008), a value of $\alpha \leq 0.6$ generally indicates unsatisfactory internal consistency and therefore a lack of reliability.

\subsection{Descriptive Properties of the Variables}

Table-2 reports descriptive statistics data for variables relating to OEMs, SPs and $\mathrm{CS}_{\mathrm{EU}}$. The variables such as $\mathrm{SQ}_{\mathrm{M}}, \mathrm{CS}_{\mathrm{M}}, \mathrm{FP}_{\mathrm{M}}, \mathrm{EL}_{\mathrm{S}}, \mathrm{FP}_{\mathrm{S}} \mathrm{SQ}_{\mathrm{EU}}$ and $\mathrm{CL}_{\mathrm{EU}}$ show high mean, low standard deviation and high values of Cronbach's alpha. Based on these preliminary data, the following observations can be made, which are later corroborated by the detailed hypothesis testing.

a. SQM will have significant impact on service delivery systems, i.e., services delivered from OEMs to SPs and from SPs to the EUs. It is apparent that SPs will be satisfied with higher value of Cronbach's alpha for SQM, and at the same time, the CSEU will rise due to increase in SQS. Hence, SPs are likely to be satisfied with OEMs performance and so the customers (i.e. End Users) with SPs' service delivery systems.

Table 2. Descriptive Statistics for OEMs, SPs and $\mathrm{CS}_{\mathrm{EU}}$

\begin{tabular}{ccccc}
\hline SN & Variables & Mean & Standard deviation & Cronbach's alpha \\
\hline 1 & $\mathrm{ES}_{\mathrm{M}}$ & 3.30 & 0.669 & 0.81 \\
2 & $\mathrm{EL}_{\mathrm{M}}$ & 3.29 & 0.904 & 0.91 \\
3 & $\mathrm{SQ}_{\mathrm{M}}$ & 3.84 & 0.569 & 0.82 \\
4 & $\mathrm{CS}_{\mathrm{M}}$ & 3.48 & 0.666 & 0.88 \\
5 & $\mathrm{CL}_{\mathrm{M}}$ & 3.42 & 0.567 & 0.85 \\
6 & $\mathrm{SR}_{\mathrm{M}}$ & 3.37 & 0.613 & 0.79 \\
7 & $\mathrm{FP}_{\mathrm{M}}$ & 3.43 & 0.698 & 0.91 \\
8 & $\mathrm{ES}_{\mathrm{S}}$ & 3.14 & 0.736 & 0.69 \\
9 & $\mathrm{EL}_{\mathrm{S}}$ & 3.53 & 0.712 & 0.74 \\
10 & $\mathrm{SQ}_{\mathrm{S}}$ & 3.41 & 0.674 & 0.71 \\
11 & $\mathrm{CS}_{\mathrm{S}}$ & 3.08 & 0.562 & 0.75 \\
12 & $\mathrm{CL}_{\mathrm{S}}$ & 3.35 & 0.511 & 0.39 \\
13 & $\mathrm{SR}_{\mathrm{S}}$ & 3.40 & 0.589 & 0.79 \\
14 & $\mathrm{FP}_{\mathrm{S}}$ & 3.52 & 0.627 & 0.699 \\
15 & $\mathrm{SQ}_{\mathrm{EU}}$ & 3.36 & 0.721 & 0.699 \\
16 & $\mathrm{CS}_{\mathrm{EU}}$ & 3.17 & 0.742 & 0.736 \\
17 & $\mathrm{CL}_{\mathrm{EU}}$ & 3.27 & 0.370 & 0.736 \\
18 & $\mathrm{SR}_{\mathrm{EU}}$ & 3.24 & 0.796 & 0.79 \\
\hline
\end{tabular}

b. Higher values of Cronbach's alpha for $\mathrm{CS}_{\mathrm{M}}$ and $\mathrm{FP}_{\mathrm{M}}$ indicate that $\mathrm{SP}_{\mathrm{S}}$ are satisfied with OEMs and are likely to repurchase and recommend OEMs' services. Most likely OEMs' sales and profitability to increase.

c. Similarly, high values of Cronbach's alpha for $\mathrm{EL}_{\mathrm{S}}$, and $\mathrm{FP}_{\mathrm{S}}$ indicate that SPs' loyal employees to take care of $\mathrm{CS}_{\mathrm{EU}}$ by delivering high quality services leading to increased sales and profitability. According to (Bamford and Xystouri, 2005), an excellent SQ can only be achieved through employee satisfaction, commitment and loyalty.

d. In the same way, high values Cronbach's alpha for $\mathrm{SQ}_{\mathrm{EU}}$ and $\mathrm{CL}_{\mathrm{EU}}$ suggest that once $\mathrm{CS}_{\mathrm{EU}}$ are satisfied, the customers turn out to be loyal, tend to repurchase and narrate positive word-of-mouth to others.

The values of Cronbach's alpha for all the variables were greater than $0.6(>0.6)$, except for $\mathrm{SR}_{\mathrm{s}}$ where it is 0.39 , which indicates that although $\mathrm{CS}_{\mathrm{EU}}$ are satisfied and loyal, they might not repurchase due to available Mobile Number Portability (MNP), i.e., switching to another carrier while retaining the current number. According to (Sese et al 2009) regulatory policy has significantly reduced the cost of switching.

\section{Verification of the Proposed Model Considering Service Chain as a Single Entity}

The following nine null hypotheses from $\mathrm{H}_{01-1}$ to $\mathrm{H}_{09-1}$ are postulated, and are subjected to standard hypothesis testing. The sections that follow present the discussion of the results and their implications. 


\section{The Upstream path represents:}

- Hypothesis $\mathrm{H}_{01-1}$ : Upstream EL affects upstream SQ

- Hypothesis $\mathrm{H}_{02-1}$ : Upstream SQ affects downstream SQ

- Hypothesis $\mathrm{H}_{03-1}$ : Upstream SQ influences downstream EL.

\section{The downstream path represents:}

- Hypothesis $\mathrm{H}_{04-1}$ : Downstream EL enhances downstream SQ

- Hypothesis $\mathrm{H}_{05-1}$ : Downstream EL enhances CSs satisfaction

- Hypothesis $\mathrm{H}_{06-1}$; Downstream SQ improves CSs satisfaction

- Hypothesis $\mathrm{H}_{07-1}$ : CSs satisfaction influences CSs loyalty

- Hypothesis $\mathrm{H}_{08-1}$ : CSs loyalty leads to downstream SR

- Hypothesis $\mathrm{H}_{09-1}$ : Downstream SR affect upstream SR

Hypothesis $\boldsymbol{H}_{01-1}$ : Upstream EL affects upstream SQ: This hypothesis examines the relationship between upstream EL and upstream $\mathrm{SQ}$, i.e., how $\mathrm{EL}_{\mathrm{M}}$ influences $\mathrm{SQ}_{\mathrm{M}}$. The data for $\mathrm{EL}_{\mathrm{M}}$ were taken from $\mathrm{OEMs}$, whereas data for $\mathrm{SQ}_{\mathrm{M}}$, were collected from SP's employees, i.e., how SPs' employees perceive SQ provided by OEMs to SPs. Accordingly, this hypothesis evaluates the impact of $\mathrm{EL}_{\mathrm{M}}$ on $\mathrm{SQ}_{\mathrm{M}}$.

The EL attribute depends on various factors and each factor may have different impact on each employee. However, the factors that are generally thought to influence EL are employees' recognition, rewards, incentives, training, skill development, future growth, job security, learning opportunities, supporting benefits and so on. These factors motivate employees to deliver higher SQ to the customers. According to (Dean and Rainnie, 2009), a balance between productivity and SQ would result from engaging employees in establishing and implementing corporate strategies.. To authenticate this hypothesis, a null hypothesis was tested using OLS regression to determine unknown parameters, in which $\mathrm{SQ}_{\mathrm{M}}$ was considered as dependent and $\mathrm{EL}_{\mathrm{M}}$ as an independent variable and the following results were obtained:

$$
\mathrm{SQ}_{\mathrm{M}}=3.477-.001 * \mathrm{EL}_{\mathrm{M}}
$$

Table 3. OLS Regression, Upstream Employee Loyalty, Upstream Service Quality

\begin{tabular}{llllllllll}
\hline \multirow{2}{*}{ Model } & \multirow{2}{*}{$\mathrm{R}$} & \multirow{2}{*}{ R-squared } & \multirow{2}{*}{$\begin{array}{l}\text { Adjusted } \\
\text { R-squared }\end{array}$} & & \multicolumn{4}{c}{ Coefficients } & \multicolumn{4}{c}{ ANOVA } \\
\cline { 5 - 10 } & & & & Const & EL $_{\mathrm{M}}$ & $\mathrm{t}$ value & Sig. & F value & Sig. \\
\hline $\mathrm{SQ}_{\mathrm{M}}$ & 0.002 & 0.000 & -0.016 & 3.477 & -.001 & 11.525 & 0.000 & -0.016 & 0.987 \\
\hline
\end{tabular}

It was observed that the path model between $\mathrm{SQ}_{\mathrm{M}}$ and $\mathrm{EL}_{\mathrm{M}}$ is well established, with global fit values of adjusted $R^{2}=-.016, F=-0.016$, at $p=0.000, E_{M}=-0.01$. The result shows an unbiased value of $R^{2}=-0.016$ and $E_{M}$ co-efficient $=-0.001$, which means that a unit change in $\mathrm{EL}_{\mathrm{M}}$ will have negligible negative influence on $\mathrm{SQ}_{\mathrm{M}}$

This also shows that only limited options are available to SPs, i.e., once SPs deploy particular OEM's network, they are virtually 'locked in' and choices for future expansion of network will be limited to the existing OEMs. This is due to network specification and employees existing skills. Hence, SPs would have no other option but to continue with existing OEM. Hence, network expansion with current suppliers will always be preferred. Thus, present results support the hypothesis that although $\mathrm{EL}_{\mathrm{M}}$ has marginal negative impact on $\mathrm{SQ}_{\mathrm{M}}$, it is not much significant. Accordingly we hold that $\mathrm{EL}_{\mathrm{M}}$ influences $S \mathbf{Q}_{\mathrm{M}}$, and has only marginal yet insignificant negative impact on $\mathbf{S Q}_{\mathrm{M}}$.

Hypothesis $H_{02-1}$ : Upstream $S Q$ affects downstream $S Q$ : This hypothesis is an extension of SPC's attributes, since it examines the influence on SQs of two different organizations, i.e. $\mathrm{SQ}_{\mathrm{M}}$ and $\mathrm{SQ}_{\mathrm{S}}$. The SPC model suggests that there are direct and strong relationships with profits, growth, CL, and CS within an organization. Data for $\mathrm{SQ}_{\mathrm{M}}$ and $\mathrm{SQ}_{S}$ were collected from two different sources, i.e. $\mathrm{SQ}_{S}$ was from EUs based on $\mathrm{SPs}$ ' features like promptness, trustworthiness, understanding of needs, fulfillment of promises and the overall demeanor of service providers, whereas $\mathrm{SQ}_{\mathrm{M}}$ data came from perception of SPs' employees' of OEM's SQ. The null hypothesis was validated using OLS regression with $\mathrm{SQ}_{S}$ as dependent and $\mathrm{SQ}_{\mathrm{M}}$ as independent variable, and it is found that:

$$
\mathrm{SQ}_{\mathrm{S}}=3.136+.132 \mathrm{SQ}_{\mathrm{M}}
$$

The result shows an unbiased value of $\mathrm{R}^{2}=-0.002$ and the $\mathrm{SQ}_{\mathrm{M}}$ coefficient $=0.132$. It shows that a unit change in $\mathrm{SQ}_{\mathrm{M}}$ will have positive impact of 0.132 on $\mathrm{SQ}_{s}$. The path model for $\mathrm{SQ}_{\mathrm{S}}$ and $\mathrm{SQ}_{\mathrm{M}}$ is well developed and indicates a global fit value of adjusted $\mathrm{R}^{2}=-0.002, \mathrm{~F}=0.928, \mathrm{p}=0.000$. This also indicates that to maintain and 
enhance $\mathrm{SQ}_{\mathrm{M}}$, SPs' employees should continuously liaise with OEMs employees. According to (Frei, 2006), to deliver consistent quality at a sustainable cost, companies must learn to manage their relationships with customers. Accordingly, it is found that $\mathrm{SQ}_{\mathrm{M}}$ affects $\mathbf{S} \mathbf{Q}_{\mathrm{S}}$.

Hypothesis $\boldsymbol{H}_{\text {03-1: }}$ Upstream $S Q$ influences downstream EL: This hypothesis looks beyond the SPC's chain as an extension of SPC's attributes. It examines the effects of $\mathrm{SQ}_{\mathrm{M}}$ on $\mathrm{EL}_{\mathrm{S}}$, i.e., how OEM's SQ influences $\mathrm{EL}_{\mathrm{S}}$. According to (Theoharakis et al., 2009), satisfied and loyal employees create meaningful relationships. The null hypothesis was tested using OLS regression to ascertain $\mathrm{EL}_{\mathrm{S}}$, in which $\mathrm{EL}_{\mathrm{S}}$ was considered as dependent and $\mathrm{SQ}_{\mathrm{M}}$ as independent variable and thus the following relation is derived:

$$
\mathrm{EL}_{\mathrm{S}}=2.427+.354 \mathrm{SQ}_{\mathrm{M}}
$$

The result shows an unbiased value of $\mathrm{R}^{2}=0.210$ with $\mathrm{SQ}_{\mathrm{M}}$ coefficient $=0.354$, which indicates that a unit change in $\mathrm{SQ}_{\mathrm{M}}$ will have a positive effect of 0.354 times on $\mathrm{EL}_{\mathrm{S}}$. It is likely that once OEMs exceed SPs' expectations, the $\mathrm{EL}_{\mathrm{S}}$ will be reinforced. According to $(\mathrm{Xu}, 2005)$, internal $\mathrm{SQ}$ is a significant factor in determining employee satisfaction.

The path model for $\mathrm{EL}_{\mathrm{S}}$ and $\mathrm{SQ}_{\mathrm{M}}$ is well established with global fit values of adjusted $\mathrm{R}^{2}=0.222, \mathrm{~F}=4.274, \mathrm{p}=$ 0.000. It indicates that to maintain $\mathrm{SQ}_{\mathrm{M}}$, the OEMs should remain continuously in contact with SPs in order to receive their feedback. Therefore, OEMs should work intelligently with SPs to meet their expectations. Accordingly, it is found that $S Q_{M}$ influences $E_{S}$.

Hypothesis $H_{04-1:}$ Downstream EL enhances downstream $S Q$ : This hypothesis examines relationship between $\mathrm{EL}_{\mathrm{S}}$ and $\mathrm{SQ}_{\mathrm{S}}$, which is an extension of conventional SPC model. The conventional model uses single source of data; but here, the data for $\mathrm{EL}_{\mathrm{S}}$ were taken from SPs employees and for $\mathrm{SQ}_{\mathrm{S}}$ from EUs, i.e., $\mathrm{SQ}$ offered by $\mathrm{SPs}$ to EUs. The null hypothesis was tested using OLS regression with SQs as the dependent and $\mathrm{EL}_{\mathrm{S}}$ as the independent variable and it is found that:

$$
\mathrm{SQ}_{\mathrm{S}}=2.874+.197 \mathrm{EL}_{\mathrm{S}}
$$

The $\mathrm{R}^{2}=0.017$ yields an unbiased result with the $\mathrm{EL}_{\mathrm{S}}$ coefficient $=0.197$, which reflects that a unit change in $\mathrm{EL}_{\mathrm{S}}$ will have a positive impact of 0.197 on $\mathrm{SQ}_{\mathrm{s}}$. It also means that satisfied and loyal employees do indeed make additional contribution to the service delivery system.

The path model for SQs and ELs is well developed with global fit values of adjusted $\mathrm{R}^{2}=0.017, \mathrm{~F}=1.041, \mathrm{p}=$ 0.000. Therefore, SQ must be maintained for better CS, which can be achieved through employees' engagement, commitment, training and skill development. Thus $\mathrm{EL}_{S}$ would eventually improve $\mathrm{SQ}_{\mathrm{s}}$. Accordingly, it is found that $\mathbf{E L}_{\mathrm{S}}$ enhances $\mathbf{S} \mathbf{Q}_{\mathrm{s}}$.

Hypothesis $\boldsymbol{H}_{\text {05-1: }}$ Downstream EL enhances CS: This hypothesis tests the extended SPC model and considers the relationship between $\mathrm{EL}_{\mathrm{S}}$ and $\mathrm{CS}_{\mathrm{EU}}$. The data for $\mathrm{EL}_{\mathrm{S}}$ and $\mathrm{CS}_{\mathrm{EU}}$ were taken from two different sources i.e. SPs' employees and EUs respectively, whereas in conventional model data are generally obtained from a single source. The null hypothesis was tested using OLS regression to identify unknown parameters by considering $\mathrm{CS}_{\mathrm{EU}}$ as dependent and $\mathrm{EL}_{\mathrm{S}}$ as the independent variable, and it is found that:

$$
\mathrm{CS}_{\mathrm{EU}}=2.194+.307 \mathrm{EL}_{\mathrm{S}}
$$

The value of $R^{2}=0.032$ shows an unbiased result with $E L_{S}$ coefficient $=0.307$. It indicates that a unit change in $\mathrm{EL}_{\mathrm{S}}$ will have an impact of 0.307 on $\mathrm{CS}_{\mathrm{EU}}$. It confirms that $\mathrm{ES}$ and $\mathrm{EL}$ will improve service delivery system, which in turn will improve $\mathrm{CS}_{\mathrm{EU}}$. Hence, $\mathrm{SPs}$ should develop plans to attract new employees and retain existing ones by introducing innovative policies and programs so that employees feel they are recognized and respected, which would support in improving EL

The path model for $\mathrm{CS}_{\mathrm{EU}}$ and $\mathrm{EL}_{\mathrm{S}}$ is well developed with global fit values of adjusted $\mathrm{R}^{2}=0.032, \mathrm{~F}=1.450, \mathrm{p}=$ 0.007. It shows that loyal employees are likely to develop a positive affiliation and improved relationship with EUs. According to (Gounaris, 2007), firms should not only focus exclusively on building and delivering functional utility to their customers but pay attention to other 'soft' dimensions as well, such as recognizing the importance of emotional value, such as "customers first" motto. Therefore, it is found that $\mathrm{EL}_{\mathrm{S}}$ will improve $\mathrm{CS}_{\mathrm{EU}}$. Accordingly, it is hypothesized that $\mathbf{E L}_{\mathrm{S}}$ enhances $\mathbf{C S}_{\mathrm{EU}}$.

Hypothesis $H_{06-1:}$ Downstream $S Q$ improves CS: Here the relationship between $\mathrm{SQ}_{\mathrm{S}}$ and $\mathrm{CS}_{\mathrm{EU}}$ is looked into. The data for $\mathrm{SQ}_{\mathrm{S}}$ and $\mathrm{CS}_{\mathrm{EU}}$ were obtained from customers in order to determine $\mathrm{CS}_{\mathrm{EU}}$. Data for typical SPC's attributes are generally taken from $\mathrm{SP}_{\mathrm{S}}$, e.g. SPs assess their own SQ and SQ as perceived by EUs. The null hypothesis was tested using OLS regression with $\mathrm{CS}_{\mathrm{EU}}$ as the dependent and $\mathrm{SQ}_{\mathrm{S}}$ as the independent variable, and the following relationship is obtained: 


$$
\mathrm{CS}_{\mathrm{EU}}=.582+.761 \mathrm{SQ}_{\mathrm{S}}
$$

The value of $\mathrm{R}^{2}=0.454$ and $\mathrm{SQ}_{\mathrm{S}}$ coefficient $=0.761$, indicating that a unit change in $\mathrm{SQ}_{\mathrm{S}}$ will have a positive effect of 0.761 times on $\mathrm{CS}_{\mathrm{EU}}$. This is remarkable due to improved $\mathrm{CS}_{\mathrm{EU}}$. Hence, SPs should develop network capability and retain skilled manpower for gaining $\mathrm{CS}_{\mathrm{EU}}$.

The path model for $\mathrm{CS}_{\mathrm{EU}}$ and $\mathrm{SQ}_{\mathrm{S}}$ is well developed and it included global fit values of adjusted $\mathrm{R}^{2}=0.446, \mathrm{~F}=$ $7.300, p=0.133$. The key to success is a focused approach to improving SQ and CS such that market share and profitability tend to increase. Accordingly, it is found that $\mathbf{S} \mathbf{Q}_{\mathrm{S}}$ improves the $\mathbf{C S}_{\mathrm{EU}}$.

Hypothesis $\boldsymbol{H}_{07-1:} \boldsymbol{C S}$ influences $\boldsymbol{C L}$ : This hypothesis identifies the relationship between CS and CL. In conventional analysis SPs provide these data, whereas EUs data were considered for this analysis. The null hypothesis was tested using OLS regression, taking $\mathrm{CL}_{\mathrm{EU}}$ as dependent and $\mathrm{CS}_{\mathrm{EU}}$ as an independent variable and it is found that:

$$
\mathrm{CL}_{\mathrm{EU}}=.740+.786 \mathrm{CS}_{\mathrm{EU}}
$$

The $\mathrm{R}^{2}=0.524$ and $\mathrm{CS}_{\mathrm{EU}}$ coefficient $=0.786$, indicating that a unit change in $\mathrm{CS}_{\mathrm{EU}}$ will have a positive impact of 0.786 on $\mathrm{CL}_{\mathrm{EU}}$. The path model for $\mathrm{CL}_{\mathrm{EU}}$ and $\mathrm{CS}_{\mathrm{EU}}$ are well developed and included global fit values of adjusted $\mathrm{R}^{2}=0.517, \mathrm{~F}=8.402, \mathrm{p}=0.024$. It indicates that $\mathrm{CS}_{\mathrm{EU}}$ contributed significantly to $\mathrm{CL}_{\mathrm{EU}}$. Therefore, SPs should take care of EUs; keep them satisfied and loyal for maintaining profitability and growth. The SPs shall maintain and improve SQ for enhancing $\mathrm{CS}_{\mathrm{EU}}$, which is a key to higher $\mathrm{CL}_{\mathrm{EU}}$. Accordingly, it is found that $\mathbf{C S}_{\mathrm{EU}}$ influences $\mathbf{C L}_{\mathrm{EU}}$.

Hypothesis $\mathrm{H}_{\text {08-1: }}$ CL leads to SR: Here the relationship between $\mathrm{CL}_{\mathrm{EU}}$ and $\mathrm{SR}_{\mathrm{S}}$, i.e., $\mathrm{CL}_{\mathrm{EU}}$ is likely to increase sales due to repurchases \& referrals look into. To validate this hypothesis, $\mathrm{CL}_{\mathrm{EU}}$ data were collected from EUs on their loyalty with their SPs, repurchase intentions and willingness to recommend services to potential buyers. While $\mathrm{SR}_{\mathrm{S}}$ data come from SPs on their view of customers' repurchase intention, it is obvious that improved $\mathrm{CL}_{\mathrm{EU}}$ will lead to increase in sales, higher profitability, lower operational costs, lower churn and reduced customer acquisition cost. The null hypothesis was tested using OLS regression, taking $\mathrm{SR}_{\mathrm{S}}$ as dependent and $\mathrm{CL}_{\mathrm{EU}}$ as independent variable, and it is found that:

$$
\mathrm{SR}_{\mathrm{S}}=.633+.797 \mathrm{CL}_{\mathrm{EU}}
$$

The value of $\mathrm{R}^{2}=0.639$ and $C \mathrm{~L}_{\mathrm{EU}}$ coefficient $=0.797$ show that a unit increase in $\mathrm{CL}_{\mathrm{EU}}$ will have positive impact of 0.797 on SR. It is logical that increased $\mathrm{CL}_{\mathrm{EU}}$ will develop positive word of mouth. The path model for $\mathrm{SR}_{\mathrm{S}}$ and $\mathrm{CL}_{\mathrm{EU}}$ is well developed and included global fit values of adjusted $\mathrm{R}^{2}=0.633, \mathrm{~F}=10.633, \mathrm{p}=0.018$.. Hence, management of customers should be given top priority to generate positive word-of-mouth for repurchases \& referrals. Accordingly, it is found that $\mathbf{C L}_{\mathbf{E U}}$ leads to $\mathbf{S R}_{\mathrm{S}}$.

Hypothesis $H_{09-1:}$ Downstream sales from SR affect upstream sales from SR: Increased purchases by EUs are likely to increase network utilization. It would require network expansion that would increase OEMs' sales. This hypothesis verifies the relationship between $\mathrm{SR}_{\mathrm{S}}$ and $\mathrm{SR}_{\mathrm{M}}$. The $\mathrm{SR}_{\mathrm{EU}}$ data were obtained from EUs, whereas $\mathrm{SR}_{\mathrm{M}}$ data were obtained from SPs on their intention to repurchase \& refer OEM. For this purpose, additional 10 questions were included in SPs' questionnaires i.e., five questions on SPs' intention to repurchase \& referral of OEMs' and another five questions on SP's assessment of customers' intention of repurchase \& referral to SPs' services.

The repurchase intentions of customers would depend on SQ, perceived service value, variety of service, price paid, and value of money. SPs can only fulfill customers' expectations if OEM is in a position to support SPs with right technology to support EUs demand. OEM should have the resources to provide VAS and most importantly, Over the Top (OTT) services. These services can make EUs feel that they get value for money. Repurchases \& referrals from EUs would require network expansion, which in turn increase OEMs' sale and $\mathrm{SR}_{\mathrm{M}}$. The null hypothesis was tested using OLS regression taking $\mathrm{SR}_{\mathrm{M}}$ as dependent and $\mathrm{SR}_{\mathrm{S}}$ as the independent variable and it is found that:

$$
\mathrm{SR}_{\mathrm{M}}=3.317+.032 \mathrm{SR}_{\mathrm{S}}
$$

The $\mathrm{SR}_{\mathrm{S}}$ co-efficient $=0.032$ indicates that an increase in $\mathrm{SR}_{\mathrm{S}}$ will have a positive impact of 0.032 on $\mathrm{SR}_{\mathrm{M}}$. The increase in $\mathrm{SR}_{\mathrm{M}}$ is lower compared to $\mathrm{SR}_{\mathrm{S}}$. This is due to the fact that $\mathrm{SPs}$ first would bundle services as peak, off-peak categories in order to distribute traffic in different time zones of the day. The objective of launching multiple packages is to postpone network expansion and utilizes network idle time. Once network utilization exceeds certain level, SPs will be forced to expand the network. The path model for $\mathrm{SR}_{\mathrm{M}}$ and $\mathrm{SR}_{\mathrm{S}}$ is well developed with global fit values of adjusted $\mathrm{R}^{2}=-0.012, \mathrm{~F}=0.507, \mathrm{p}=0.000$. The primary goal for OEMs and 
SPs is to enhance CS and CL that would encourage repurchases and referrals. Accordingly, it is found that $\mathbf{S R}_{\mathbf{S}}$ affects $\mathbf{S R}_{\mathrm{M}}$.

\section{Discussion and Conclusions}

Looking at the current literature one finds that research on entire SPCs has been limited and most of the researchers have restricted themselves exclusively to ES, CS, SQ, or employees evaluating customer perceptions of SQ etc. In most of the studies, data were obtained from a single source, e.g., employees evaluating customers' perceptions of SQ and their own satisfaction and loyalty. These issues prompted the authors to conduct a comprehensive study on extended SPC's chain. The present study thus validates the impact of EI on extended SPC's service chain. The extended SPC's chain is formed by considering both uplink and downlink paths and the services are provided from OEMs to SPs and from SPs to the customers. Therefore, the present research may be deemed to have successfully attempted to evaluate the influence of EI on SPC's attributes and goes even beyond it by testing the extended SPC's attributes.

Also, in some cases, the studies were limited to only a few attributes of SPCs, though a few exceptions do exist in the literature such as (Yee, 2006), whose findings suggest that employee satisfaction and loyalty have a direct impact on SQ and CS, and CS and loyalty contribute to customer repurchases \& referrals and enhanced firm profitability. Similarly, a study by (Homburg et al., 2009) brings out the positive role played by social identification construct in developing strong customer relationships which led to positive market and financial outcome.

\subsection{Research Findings}

Emotional Intelligence is widely seen to consolidate employees' emotion. It has the potential to empower and encourage them to reach perfection in their performance. The bearing of EI on the organization was measured on extended SPC's chain, thus providing an evidence in support of the assumptions and hypotheses as formulated in this work. The research was performed using different research instruments and concluded with the implications of statistical testing of various hypotheses.

The research findings suggest that the telecom service industry should view SPCs' attributes as its strategic and tactical asset. And SPs should continuously monitor SQ to maintain level of EUs satisfaction, which can be achieved through employee training, retraining and skills development. The service organizations should pursue EL in earnest, as loyal employees are likely to develop better relationships with customers and it can lead to improved SQ for SPs and OEMs as well.

The research findings also suggest that an increase in $\mathrm{SQ}_{M}$ will proportionately increase $\mathrm{SQ}_{S}$ and $\mathrm{EL}_{\mathrm{S}}$. Increased $\mathrm{EL}_{\mathrm{S}}$ will lead to increase in $\mathrm{SQ}_{\mathrm{S}}, \mathrm{CS}_{\mathrm{EU}}$ and $\mathrm{CL}_{\mathrm{EU}}$. Higher $\mathrm{CL}_{\mathrm{EU}}$ will help improve $\mathrm{SR}_{\mathrm{S}}$, which would in turn trigger increase in $\mathrm{SR}_{\mathrm{M}}$. It is also observed that once SPs' employees are satisfied, they would be willing to deliver best possible services to customers. This will promote increase in CS, CL, SR and positive word-of-mouth to potential customers. The upshot of this study is that EI, acting as a pivotal background concept in the extended SPC model, integrates influences and reinforces many attributes spanning over three major players, in a way that brings to force the internal dynamics of interactions among the relevant entities in the system. The present work thus reemphasizes and reiterates the unifying and universal role of EI. It also demonstrates and exemplifies the usefulness and usability of SPC in the ecosystem of service oriented industries.

Hence, EI must be given due importance in any service industry. The SPC's and extended SPC's attributes should be measured frequently on a regular basis in a service industry and corrective action should be initiated accordingly. The results of all hypotheses are in line with the assumptions and in conformity with SPC's linkages of (Heskett et al., 1994), thus confirming that highly satisfied customers drive growth and profitability in service businesses, and to keep them profitable, it is necessary to manage SPC.

\section{Limitations and Future Research}

The research was conducted in the fast growing telecom service industry which is witnessing rapid changes with time, and is vigorously making effort to keep abreast of unprecedented, breathtaking technological developments. In this modern IT era, it goes without saying that telecom has become an essential, vital service and plays a pivotal role in supporting socio-economic development of a nation.

Like any other research, this work too has its own share of limitations that need to be spelt out. The questionnaires were written in English, special efforts being made to use simple language within a limited core English vocabulary. Despite deliberate simplicity of language used, it is likely that some of the respondents might have had the feeling of being daunted by the English language, and therefore some questions appeared either not clear to them or possibly not properly explained by the volunteers. As a result, their responses might not accurately reflect 
their feelings and intentions.

All possible efforts were made to collect samples proportionately from OEMs and SPs based on their employee strength. Feedback from EUs were obtained from all segments of society, and in some cases, questionnaires for EUs might have not been uniformly distributed. The responses from EUs were aggregated ignoring the contrasts such as corporate $v s$. home users, their local $v s$. expatriate status, and glossing over differences in gender, age group as well as professional and educational backgrounds of respondents.

This research was carried out in a typical telecom service organization where some of the tech-savvy customers might have obtained services through web portal or by using short codes provided by SPs, which would have led to a feeling of better CS for them. Those customers would have not been satisfied to the same extent, had they interacted with customer representatives at the normal, regular outlets.

Future research can explore labour-intensive service industries or focus on poorly satisfied or somewhat disgruntled employees who are keen on switching to other jobs. It can be further extended to production linked service industry as well to elucidate the linkages between EI and SPC. The present work can be seen as a step towards encouraging further research and to construct more detailed or refined theories on effect of EI on SPC and extended SPC chain

\section{Acknowledgements}

The researchers are thankful to the executives and employees of OEMs, and SPs for their participation in this survey project. Our special thanks go to the telecom service providers and OEMs for their co-operation. Thanks are also due to friends and their family members for their help and assistance, and for sparing their time in collecting data from end users. Finally, our customers and EUs certainly deserve special thanks for their valuable contributions.

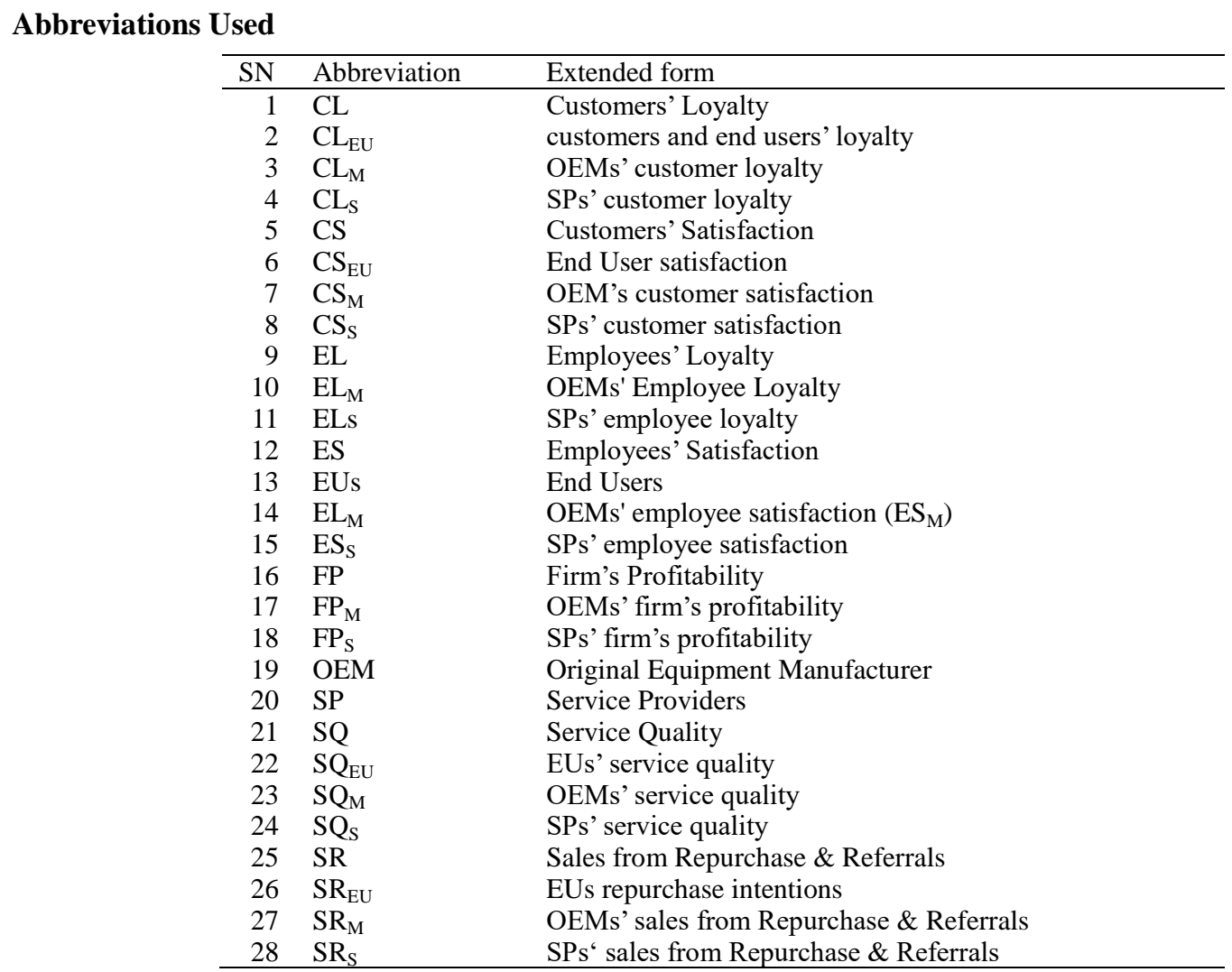

\section{References}

Ansari, M. S. A., Farooquie, J. A., \& Gattoufi, S. M. (2016). Does Emotional Intelligence Influence Employees, Customers and Operational Efficiency: An Empirical Validation. International Journal of Marketing Studies, 8, 77-88. https://doi.org/10.5539/ijms.v8n6p77

Bamford, D., \& Xystouri, T. (2005). A case study of service failure and recovery within an international airline. Managing Service Quality, 15, 306-322. https://doi.org/10.1108/09604520510597845

Bressolles, G., \& Durrieu, F., (2015). An examination of the online service-profit chain. International Journal of 
Retail \& Distribution Management, 43, 727-751, https://doi.org/10.1108/IJRDM-11-2013-0214

Chicu, D., Valverde, M., \& Ryan, G. (2016). The service-profit chain in call centre services. Journal of Service Theory and Practice, 26(5), 616-641. https://doi.org/10.1108/JSTP-10-2014-0243

Chu, G., Cleff, T., \& Walter, N. (2013). Brand experience‘s influence on customer satisfaction and loyalty: a mirage in marketing research. International Journal of Management Research and Business Strategy, 2(1), $130-144$.

Clements, M. E. (2004). Local telephone quality-of-service: a framework and empirical evidence. Telecommunications Policy, 28, 413-426. https://doi.org/10.1016/j.telpol.2004.02.001

Cliffe, S. J., \& Motion, J., (2005). Building contemporary brands: a sponsorship- based strategy. Journal of business research, 58, 1068-1077. https://doi.org/10.1016/j.jbusres.2004.03.004

Dean, A. M., \& Rainnie, A. (2009). Frontline employees' views on organizational factors that affect the delivery of service quality in call centers. Journal of Services Marketing, 23(5), 326-337, https://doi.org/10.1108/08876040910973431

Duffy, D. L. (1998). Customer loyalty strategies. Journal of consumer marketing, 15(5), $435-448$. https://doi.org/10.1108/07363769810235910

Evanschitzky, H., Wangenheim, F. V., \& Wunderlinch, N. V. (2012). Perils of Managing the Service Profit Chain. The Role of Time Lags and Feedback Loops. Journal of Retailing, 88(3), 356-366. https://doi.org/10.1016/j.jretai.2012.01.003

Harvard Business Review: Goleman, D. (2004). What Makes a Leader, Brighton, USA, (JANUARY 2004 ISSUE), https://hbr.org/2004/01/what-makes-a-leader

Harvard Business Review: Goleman, D., \& Boyatzis, R. (2008). Social Intelligence and the Biology of Leadership, Brighton, USA, (September 2008).

https://hbr.org/2008/09/social-intelligence-and-the-biology-of-leadership

Harvard Business Review: Reichheld, F. (2006). “The Ultimate Question", Brighton, USA

Harvard Business Review; Frei, F. X. (2006). Breaking the trade-off, Between Efficiency and Service, Brighton, USA, (November 2006 ). https://hbr.org/2006/11/breaking-the-trade-off-between-efficiency-and-service

Heskett, J. I., Jones, T. O., Loveman, G. W., Sasser, W. E., \& Schlesinger, L. A. (1994). Putting the Service Profit Chain to Work. Harvard Business Review, 72(2), March-April 1994, 164-174. https://hbr.org/2008/07/putting-the-service-profit-chain-to-work

Heskett, J. L., Sasser, W. E., \& Schlesinger, L. A. (1997). The Service Profit Chain, How leading companies Link Profit and Growth to Loyalty. Satisfaction and Value, Free press, New York: https://www.hbs.edu/faculty/Pages/item.aspx?num=284

Homburg, C., Wieseke, J., \& Hoyer, W. D. (2009). Social Identity and Service Profit Chain. Journal of Marketing. American Marketing Association, 73(2), 38-54, 1-44. https://doi.org/10.1509/jmkg.73.2.38

Kamakura, W. A., Mittal, V., Rosa, F. D., \& Mazzon, J. A. (2002). Assessing the Service-Profit Chain. Marketing Science, 21(3), 294-317. https://doi.org/10.1287/mksc.21.3.294.140

Karpinski, R. I., Kolb, A. M. K, Tetreaulr, N. A., \& Borowski, T. B. (2017). High intelligence, A risk factor for psychological and physiological over excitabilities. Intelligence.

Kassinis, G. I., \& Soteriou, A. C. (2003). Greening the service profit chain. The impact of environmental management practices. Production and operation management, 12(3), 386-403,

Khatibi, A. A., Ismail, H., \& Thyagarajan, V. (2002), what drives customer loyalty: An analysis from the telecommunications industry, Journal of Targeting. Measurement and Analysis for Marketing, 1, 34-44. https://doi.org/10.1057/palgrave.jt.5740065

Kim, D., \& Sugai, P. (2008). Differences in consumer loyalty and willingness to pay for service attributes across digital channels: A study of the Japanese digital content market. Telecommunications Policy, 32, 480-489. https://doi.org/10.1016/j.telpol.2008.05.003

Lee, H. S. (2013). Major Moderators Influencing the Relationships of Service Quality, Customer Satisfaction and Customer Loyalty. Canadian Center of Science and Education. Asian Social Science, 9(2), 1-11. https://doi.org/10.5539/ass.v9n2p1 
Loveman, G. W. (1998). Employee satisfaction, customer loyalty and financial performance: An empirical examination of the service profit chain in retail banking. Journal of service research, 1(1), 18-31, https://doi.org/10.1177/109467059800100103

Maritz, A., \& Nieman, G. (2008). Implementation of service profit chain initiatives in a franchise system. Journal of Services Marketing, 22(1), 13-23. https://doi.org/10.1108/08876040810851923

Marketing Research; Malhotra, N. K., \& Birk, D. F. (2008). An applied approach, Georgia Institute of Technology, $4^{\text {th }}$ edition.

Onyeajuwa. M. K. (2017), Institutions and consumers: Assertion of ordinary consumer interest in the Nigerian digital mobile telecommunications market. Telecommunications Policy, 41, 642-650. https://doi.org/10.1016/j.telpol.2017.05.004

Pilkington, A., \& Chai, K. H. (2008). Research Themes, concepts and relationships. International Journal of Service, Industry Management, 19(1), 83-110. https://doi.org/10.1108/09564230810855725

Rygielski, C., Wang. J. C., \& Yen, D. C. (2002). Data mining techniques for customer relationship management. Technology in society, 24, 583-502. https://doi.org/10.1016/S0160-791X(02)00038-6

Saraei, S., \& Amini, A. M. (2012). A study of service quality in rural ICT renters of Iran by SERVQUAL. Telecommunications Policy, 36, 571-578. https://doi.org/10.1016/j.telpol.2012.03.002

Sese, J., Maicas, P. P, Polo, Y., \& Javier, F. (2009). Reducing the level of switching costs in mobile communications: The case of Mobile Number Portability. Telecommunications Policy, 33, 544-554. https://doi.org/10.1016/j.telpol.2009.04.003

Sharif, K. (2009). Relationship Between Intra-and Inter-organizational Service Quality Perceptions: An Empirical Testing of Modified Service Profit Chain Model Within Kuwaiti Telecommunications Industry. Services Marketing Quarterly, 30, 249-269. https://doi.org/10.1080/15332960902993502

Silvestro, R., \& Cross, S. (2000). Applying the service profit chain in retail environment: Challenging the satisfaction mirror. International Journal of Service Industry Management, 11(3), 244-268. https://doi.org/10.1108/09564230010340760

Sloan Management Review: Schlesinger, L. A., \& Heskett, J. L. (1991). Breaking the cycle of failure in service, 32(3), 17-28. https://sloanreview.mit.edu/article/breaking-the-cycle-of-failure-in-services

Theoharakis, V., Sajtos, L., \& Hooley, G. (2009). The strategic role of relational capabilities in the business-to-business service profit chain. Industrial marketing management, 38, 914-924. https://doi.org/10.1016/j.indmarman.2009.04.006

Walker, R. H., Johnson, L. W., \& Leonard, S. (2006). Re-thinking the conceptualization of customer value and service quality within the service profit chain. Managing Service Quality, 16(1), 23-36. https://doi.org/10.1108/09604520610639946

Williams, P., \& Naumann, E. (2011). Customer satisfaction and business performance: A firm-level analysis. Journal of Service Marketing, 25(1), 20-32. https://doi.org/10.1108/08876041111107032

Xu, Y. (2005). The Employee Factor in the Service-Profit Chain Framework: A Study Among Service Employees Working Within a Leading Chinese Securities Firm. Journal of International Consumer Marketing, 18(1/2), 137-155. https://doi.org/10.1300/J046v18n01_07

Yee, R. W. Y., Yeung, A. C. L., \& Cheng, C. E. C. (2008). The impact of employee satisfaction on quality and profitability in high-contact service industries. Journal of Operations Management, 26, 651-668. https://doi.org/10.1016/j.jom.2008.01.001

Yee, R. W. Y., Yeung, A. C. L., \& Cheng, E. C. E (2011). Service Profit Chain: An empirical Analysis in high contact service industries. International Journal of Production Economics, 130, 236-245. https://doi.org/10.1016/j.ijpe.2011.01.001

Yee, R. W. Y., Yeung, A. C. L., Cheng, C. E. C., \& Lai, K. H. (2009). The service-profit chain: A review and extension. Total Quality Management, 20(6), 617-632. https://doi.org/10.1080/14783360902924259

\section{Copyrights}

Copyright for this article is retained by the author(s), with first publication rights granted to the journal.

This is an open-access article distributed under the terms and conditions of the Creative Commons Attribution license (http://creativecommons.org/licenses/by/4.0/). 